Article

\title{
Evaluation of HVAC Design Parameters in High-Performance Hospital Operating Theatres
}

\author{
Gonzalo Sánchez-Barroso and Justo García Sanz-Calcedo * \\ Industrial Engineering School, University of Extremadura, 06007 Badajoz, Spain; gsanchezbmorenol@gmail.com \\ * Correspondence: jgsanz@unex.es; Tel.: +34-924-289-300
}

Received: 27 January 2019; Accepted: 5 March 2019; Published: 12 March 2019

check for updates

\begin{abstract}
Unidirectional flow air-conditioning systems are suitable for achieving indoor air quality required in high-performance operating rooms (organ transplants, cardiac surgery, aorta, orthopedic, burns, etc.). This paper analyzes indoor environmental conditions and technical and hygienic requirements for the design of heating, ventilation, and air-Conditioning (HVAC) systems for high-performance operating theatres. The main standards applicable to this type of operating rooms were compiled. Standard UNE 100713:2015, ASHRAE Standard 170-2017, and the European pre-norm EN 16244 were analyzed. A case study shows the lack of uniformity in design criteria and their ranges of values, which generates different design approaches. It was concluded that using these standards applicable to high-performance operating rooms leads to very different indoor environmental conditions for patients and medical personnel—air velocity profiles, air movement pattern, temperature, relative humidity gradients, and pressure stratification. Computational fluid dynamics (CFD) studies have been shown to detect areas of haven that favor microbiological load accumulation. In this way, it is possible to define cleaning protocols to attend these anomalies in a preventive way.
\end{abstract}

Keywords: healthcare facilities; IAQ; HVAC; CFD; healthcare engineering

\section{Introduction}

The heating, ventilation, and air-Conditioning (HVAC) system of a hospital operating theatre determines the level of sepsis that can be achieved in the surgical field [1]. There is a correlation between ventilation systems and the degree of contamination of the surgical wound [2,3]. Thus, high-performance hospital operating rooms have the appropriate HVAC system, usually unidirectional flow [4], to develop complex surgeries due to the high level of sepsis reached in the surgical field. Indoor air quality (IAQ) of a surgical room is directly related to the risk of acquiring a nosocomial infection [5]. A minimum level of microbiological load is needed in operating theatres to avoid surgical site Infections (SSI) [6,7], therefore international standards include recommended maximum values. SSIs are mainly caused by airborne bioparticles [8]. The risk of getting a nosocomial infection is conditioned by several factors-the patient himself, due to his state of health (immune system), the characteristics of the room where he/she is (degree of cleanliness and presence of contaminants), factors relating to medical procedures (techniques and their application, clothing and protective elements, etc.), factors relating to HVAC system (air changes per hour, air movement pattern, air residence time, etc.) [4], sectioning of the surgical block, and construction works in the facilities [9]. SSI rate is one of the indicators used internationally to quantify the quality of medical services [10].

Airborne bioparticles' origin can be twofold—emitted by people inside the room and/or coming from the outside environment through HVAC system supply air [11,12]. Medical staff on site wear clothing that minimizes the spreading of particles from their own body, however, the patient is undressed. In this way, particles generated by both can get into the surgical wound and cause an SSI. 
This is aggravated if an adequate level of preoperative room cleanliness has not been achieved [13,14]. Main pathogens present in operating theatres are bacteria, such as Staphylococcus aureus, and fungi, as Aspergillus sp. [15]. These pathogens are distributed in air using airborne bioparticles emitted by people within the room as a vector [16]. In order to prevent bioparticles' entrance through the drive system, the number of recommended filter stages and their efficiency are defined in the high-performance air-conditioning standards.

IAQ requirements go beyond ensuring comfortable thermohygrometric conditions. Monitoring additional environmental parameters in order to meet asepsis level and air quality required by operating room users is necessary for high-performance air-conditioning systems. There are differing requirements regarding thermohygrometric conditions since heating and cooling are demanded independently of the external seasonal regime because of specifications of certain surgeries, for instance, heart surgery, which requires low ambient temperatures. Surgical interventions on patients with immune system disorders require a protective environment in the room they occupy so complexity increases. High-performance operating theatres are suitable for organ transplantation, cardiac and aortic surgery, and orthopedic surgery. Therefore, HVAC systems become an effective tool for controlling SSI in high-performance operating rooms. Water source heat pump (WSHP) systems can integrate to meet the demand for air-conditioning operating rooms safely [17].

According to the American Society of Heating, Refrigerating, and Air-Conditioning Engineers (ASHRAE), the distribution of temperature, relative humidity, air velocity values, and pollution levels in the room environment determine its IAQ [18]. Positive differential pressure in the room with respect to adjacent spaces is established to promote operating room protection and prevent microorganisms' entrance from adjoining rooms (cross-contamination). Air movement from the protected area-the operating theatre-towards the outside is achieved. In addition, controlling aerosols, anesthetic gases, and surgical smoke concentration is necessary to ensure adequate IAQ [19]. The parameters that must be controlled in high-performance air-conditioning for operating rooms are temperature, relative humidity $(\mathrm{RH})$, air changes per hour $(\mathrm{ACH})$, outdoor air $(\mathrm{OA})$, pressurization, levels of filtering, air movement pattern, air movement among rooms, and microbiological loads. The relative humidity in indoor air must be controlled to reduce the risk of airborne infections [20].

IAQ of a high-performance operating theatre can be evaluated on the basis of the thermal comfort felt by personnel inside. For this purpose, "predicted mean vote" and "predicted percentage of dissatisfied" derived from the Fanger's comfort equation are usually calculated [21]. However, these methods are usually applied to air-conditioning where thermal comfort prevails over other criteria. Medical-surgical criteria must prevail over thermal comfort criteria in surgical suites. SSI over the total number of surgical operations performed in a given room is another criterion for evaluating HVAC system performance. As a disadvantage, this criterion is applied posteriori, so it is not useful to prevent SSI. Nevertheless, computational fluid dynamics (CFD) technology allows us to model air pattern, its thermohygrometric conditions, and bioparticle transport phenomena produced by the air movement in the room. CFD is a utility to evaluate the effectiveness of HVAC system applied to the air-conditioning of high-performance operating rooms during the design phase [22].

There is no single international standard describing technical recommendations applied to operating room HVAC systems design. Different countries or regions define their own standards. There are other standards related to the high-performance air-conditioning of cleanrooms. Recommendations for cleanrooms in pharmaceutical, microelectronics, and aerospace industries are commonly used in hospital environments. ISO 14644 series of standards are widely used as a reference in the surgical suite context. Cleanrooms and operating suites are compatible because they share technical and hygienic specifications. However, ISO 14644 is specific for industrial white rooms air-conditioning [23].

The first standard for cleanroom air-conditioning was NASA standard for clean rooms and work station for medical controlled environment (NHB 5340.2) [24]. Many standards arose from this that deal with filters' efficiency or maximum microbiological load allowed in this type of rooms. For instance, France and Belgium, NF S 90-351: Clean rooms and related controlled 
environments in medical establishments [25]; Germany, DIN 1946: Ventilation and air-conditioning Part 4: Ventilation in hospitals [26]; Switzerland, SWKI 99-3: Heating, ventilation, and air-conditioning in hospitals [27]; Japan, JIS-B 9920: Classification of air cleanliness for cleanrooms [28]; Italy, UNI 11425:2011: Pollution-controlled air-conditioning and ventilation system (CCPV) for the operating block-Design, installation, commissioning, qualification, operation, and maintenance [29]; United Kingdom and Ireland, HTM 01-03 Heating and ventilation systems: Specialized ventilation for healthcare premises [30].

Melhado et al. reviewed standards about operating room ventilation systems design [31]. Information provided in European and South American country standards and ASHRAE Standard was summarized. They analyzed the requirements and their relationship to infection risk. They concluded that defining the ideal values for each parameter was difficult because each standard proposes different values. Nastase et al. conducted a review of the main European standards on operating theatres' HVAC systems design and operation with special treatment to those applicable in Romania [32]. Lack of uniformity in existing standards do not impose strict values as would be appropriate and lack specifications of certain parameters were their conclusions. They suggest a re-edition of existing standards based on experience but considering current on-site issues. Balaras et al. collected recommendations from guidelines and standards about design, installation, commissioning, operation, and maintenance of HVAC facilities in hospital surgical rooms [33]. They matched their work with the monitoring of 20 operating theatres of 10 Hellenic hospitals, detecting inadequate indoor thermal conditions, insufficient air renewals, and poor maintenance plans. Khodakarami and Nasrollahi presented a literature review about thermal comfort in hospitals [34]. They concluded that existing studies do not consider people with different requirements being in the same room and, consequently, they propose research that reconciles this shortcoming. Iudicello and Fadda made a roadmap through the requirements of some European standards on the design of ventilation systems for operating suites [35]. They highlighted the difficulty of evaluating an air diffusion system effectiveness in controlling SSI using a general abstract model. However, no precedent studies have been found where standardized design parameters of HVAC facilities for high-performance hospital operating rooms were compared.

The aim of this work is to carry out a comparative analysis of technical and hygienic requirements recommended by different international standards to achieve adequate indoor environmental conditions in high-performance hospital operating theatres. In addition, the difference in criteria is shown through a case study that makes it possible to determine the best choice in the design phase of hospital infrastructures. The results will be useful for designers, managers, and maintenance responsible for this type of installations.

\section{Materials and Methods}

National and international standards were studied to analyze technical and hygienic recommendations for designing HVAC systems applied to the conditioning of high-performance operating theatres. Specifically, technical and hygienic requirements from standards UNE 100713:2005 Air conditioning in Hospitals [36], ASHRAE Standard 170-2017 Ventilation of Health Care Facilities [37], and y EN 16244 Ventilation in Hospitals [38] were presented, analyzed, and discussed. Furthermore, information published in guidelines, books, and papers was related to the current requirements for discussing its practical applicability.

The standard UNE 100713 is currently in force in Spain since September 2005 when the 2003 version was replaced. Standard EN 16244 advanced drafts exist, and a Technical Specification (TS) document is already published. The 2017 version is the latest update of ASHRAE Standard 170. Table 1 shows the specifications of the standard used in the research. 
Table 1. Specification.

\begin{tabular}{|c|c|c|c|c|}
\hline Standard & Name & Institution & Latest Version & Version Number \\
\hline UNE 100713 & $\begin{array}{c}\text { Air Conditioning in } \\
\text { Hospitals }\end{array}$ & $\begin{array}{l}\text { Spanish Association of } \\
\text { Standardization } \\
\text { (AENOR) }\end{array}$ & 2005 & 2 \\
\hline $\begin{array}{c}\text { ASHRAE Standard } \\
170\end{array}$ & $\begin{array}{l}\text { Ventilation of Health } \\
\text { Care Facilities }\end{array}$ & ASHRAE & 2017 & 4 \\
\hline EN 16244 & Ventilation in Hospitals & $\begin{array}{l}\text { European Committee } \\
\text { for Standardization }\end{array}$ & 2018 & 1 \\
\hline
\end{tabular}

CFD technology was employed to quantitatively evaluate HVAC system design functioning according to indoor environmental conditions proposed by these three standards using software ANSYS Fluent. A pressure-based coupled steady-state algorithm was employed for multi-species (dry air and water vapor) numerical model. The Reynolds-Averaged Navier-Stokes (RANS) approach was applied to fluid flow govern equations using a standard k- $\varepsilon$ [39] turbulence model and standard function for fluid flow treatment near wall [40]. The Boussinesq model was assumed as buoyancy modeling [41]. Boundary conditions implemented to numerical models differed in each of the three designs proposed as indicated in the Case Study. For these conditions, equations of continuity, momentum, energy, turbulent kinetic energy $(k)$, turbulence dissipation rate $(\varepsilon)$, and species are expressed in general form in Equation (1), and specification for source term $S_{\Phi}$ and effective diffusion coefficient $\Gamma_{\Phi}$ for variable $\Phi$ are in Table 2 [42]:

$$
\frac{\partial}{\partial t}(\rho \Phi)+\frac{\partial}{\partial x_{j}}\left(\rho U_{j} \Phi\right)=\frac{\partial}{\partial x_{J}}\left(\Gamma_{\Phi} \frac{\partial \Phi}{\partial x_{j}}\right)+S_{\Phi}
$$

where $u_{j}(j=1,2$, and 3$)$ are the three components of momentum $(u, v, w), T$ is mean temperature, $k$ is turbulent kinetic energy, $\varepsilon$ is turbulence dissipation rate, $C$ is species concentration, $\mu$ is kinematic viscosity, $\mu_{t}$ is turbulent viscosity, $P$ is mean pressure, $x_{i}$ and $x_{j}$ are spatial coordinates in the $i$ and $j$ direction, $\rho$ is density, $g_{i}$ is component $i$ of the gravitation vector, $\beta$ is thermal expansion coefficient, $T_{0}$ is operating temperature, $S_{T}$ is source term for temperature, $S_{C}$ is the source term for species, $G_{k}$ is the generation of turbulent kinetic energy because of the mean velocity gradients, $G_{B}$ is the generation of turbulent kinetic energy due to buoyancy, $U_{i}$ and $U_{j}$ are components $i$ and $j$ of the mean velocity, $C_{1 \varepsilon}$, $C_{2 \varepsilon}$, and $C_{3 \varepsilon}$ are constants of $\varepsilon$-equation, $C_{\mu}$ is the constant used for calculating $\mu_{t}, \sigma_{1}$ is the turbulent Schmidt number, $\sigma_{t}$ is the energy Prandtl number, $\sigma_{k}$ is the Prandtl number of $k, \sigma_{\varepsilon}$ is the Prandtl number of $\varepsilon$, and $\sigma_{C}$ is the species Prandtl number.

Table 2. Specification of standard k- $\varepsilon$ model parameters.

\begin{tabular}{|c|c|c|c|}
\hline 5 March 2019 & $\Phi$ & $\Gamma_{\Phi}$ & $S_{\Phi}$ \\
\hline Equation Continuity & 1 & 0 & 0 \\
\hline Equation Momentum & $u_{i}(i=1,2,3)$ & $\mu+\mu_{t}$ & $-\frac{\partial P}{\partial x_{i}}-\rho g_{i} \beta\left(T-T_{0}\right)$ \\
\hline Equation Temperature & $T$ & $\frac{\mu}{\sigma_{1}}+\frac{\mu_{t}}{\sigma_{t}}$ & $S_{T}$ \\
\hline k-Equation & $k$ & $\frac{\mu+\mu_{t}}{\sigma_{k}}$ & $G_{k}-\rho \varepsilon+G_{B}$ \\
\hline$\varepsilon$-Equation & $\varepsilon$ & $\frac{\mu+\mu_{t}}{\sigma_{\varepsilon}}$ & $\frac{\varepsilon}{k}\left[\left(C_{1 \varepsilon} G-C_{2 \varepsilon} \rho \varepsilon\right)+C_{3 \varepsilon} G_{B}\right]$ \\
\hline Equation Species & C & $\frac{\mu+t_{t} \mu_{t}}{\sigma_{C}}$ & $S_{C}$ \\
\hline $\begin{array}{c}\mu_{t}=\frac{\rho C_{\mu} k^{2}}{\varepsilon} \\
G_{k}=\mu_{t}\left(\frac{\partial U_{i}}{\partial x_{j}}+\frac{\partial U_{j}}{\partial x_{i}}\right) \frac{\partial U_{i}}{\partial x_{j}} \\
G_{B}=\beta g_{i} \frac{\mu_{t}}{\sigma_{t}} \frac{\partial T}{\partial x_{i}}\end{array}$ & $\begin{array}{l}C_{1 \varepsilon}= \\
C_{2 \varepsilon}= \\
C_{3 \varepsilon}= \\
C_{\mu}=\end{array}$ & & $\begin{array}{l}\sigma_{1}=0.7 \\
\sigma_{t}=0.9 \\
\sigma_{k}=1.0 \\
\sigma_{\varepsilon}=1.3 \\
\sigma_{C}=1.0\end{array}$ \\
\hline
\end{tabular}




\subsection{Standard UNE $100713: 2015$}

Standard UNE 100713 was composed by National Technical Committee "CTN 100-Conditioning" and belongs to International Classification of Standards "ICS 91.140.30/Ventilation and Air-Conditioning Systems". On the one hand, it proposes a series of physiological and hygienic requirements and, on the other, technical requirements. In order to achieve each one, a series of characteristics and requirements specific to each requirement are listed. First, physiological and hygienic requirements proposed by UNE 100713 are thermal comfort, air quality, and sound pressure level. Secondly, there are seven technical and hygienic requirements-OA intakes and exhaust air outlets, air ducts, closing dampers, smoke extraction ducts and fire dampers, components of air conditioning systems, air-conditioning systems in operating rooms, and operation of air-conditioning systems in special cases.

\subsection{Pre-Standard EN 16244}

The set of standards EN 16244 Ventilation in hospitals have been drafted by CEN-TC 156-WG 18 and is structured by the TS document and initially by five parts: Part $1-$ General requirements, Part 2-Operating suites, Part 3-Isolation rooms, Part 4-Sterilization room, and Part 5-Treatment room. The TS document creates a framework within which the parts of the standard are structured and developed. TS document defines new terms-critical zone (surgical table and sterile instruments), protected zone (incident area from air diffuser), and periphery area (anesthetist and other equipment and staff circulating zone)—used to define requirements depending on zones.

With regard to HVAC systems design, the TS document describes in detail four phases for conditioning installations project in surgical rooms, lists proposed targets of each single phase and appoints who should be in charge. Project phases, specific activities to each one, and how they are distributed along time and the level of abstraction necessary to project development according to "V-Model" project management methodology is schematized in Figure 1.

Part 1 describes the minimum requirements for ventilation systems in terms of the minimum specifications required by the user, the functional design requirements, and the requirements for the components in the detailed design. Part 2 adapts the technical requirements of each phase defined in Part 1 to operating theatre. In EN 16244-2, the so-called physiological and hygienic requirements are addressed in performance requirements of the ventilation system and the so-called technical and hygienic requirements are addressed as requirements of the system components. Specifically, Part 2 addresses the following hygienic issues related to ventilation systems: (i) air quality, (ii) patient and staff protection from infectious agents, (iii) microorganism growth reduction, and (iv) airflow direction control.

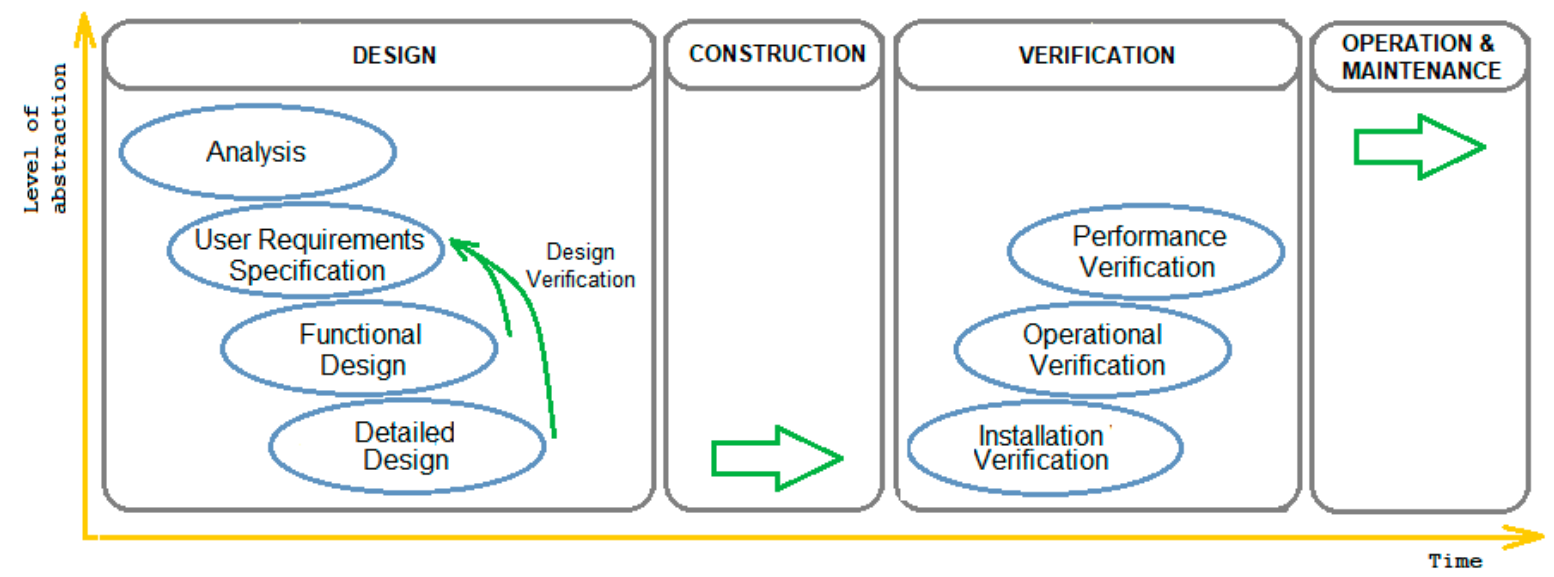

Figure 1. Heating, ventilation, and air-conditioning (HVAC) installations project according to V-Model. 
The pre-standard sets out two levels of cleanliness required for an operating room-clean air and ultra-clean air. The air cleanliness level required for an operating room should minimize the chances of contracting an SSI. For each cleaning level, one of two contaminant removal strategies may be used-unidirectional and multidirectional flow ventilation systems. It should be noted that the standard calls them protected area system and air dilution system, respectively. The pre-standard recommends the consideration of factors related to personnel and equipment influence when choosing the ventilation strategy of an HVAC system.

Depending on the required cleanliness level and the chosen ventilation strategy, a number of hygienic and technical requirements are defined. These may vary, depending on whether the operating room is functioning or at rest. When an operating theatre is in operation, requirements are just hygienic and set an upper limit for microbiological load concentration based on ISO 14698 [43]. With an operating theatre is on standby, requirements are both hygienic and technical, and refer to microbiological load, particle concentration, segregation test, room recovery test, and operating room-lamp wake recovery test.

\subsection{ASHRAE Standard $170-2017$}

Design criteria for environmental control of comfort, asepsis, and odor are proposed in ANSI/ASHRAE/ASHE Standard 170-2017 Ventilation of Health Care Facilities [37]. The book "HVAC Design Manual for Hospitals and Clinics" [18] is the basis of the standard. The standard describes general design criteria, and then they are specified according to application-hospital spaces, outpatient spaces, and nursing home spaces. Recommended values for the design parameters of operating theatre air conditioning (physiological and hygienic requirements) are given in hospital spaces. Furthermore, construction criteria for the arrangement of diffusers and extractions in the room, known as technical requirements, are defined. For this work, we used those referred to hospital spaces.

\subsection{Quantitative Requirements of the Standards}

A comparison between each key parameter value in operating room conditioning according to the Spanish standard, the ASHRAE Standard, and the European pre-standard are shown in Table 3.

Technical and hygienic prerequisites that are listed and described in UNE 100713 used as requirements for ventilation system components in the new EN 16244 are ducts, end filters, air supply terminal devices, air exhaust devices, local recirculation fans, acoustic attenuators and doors, and air leakage. In addition, new ones have been introduced-overflow openings, heating systems for cold spaces and ceilings, doors and their slits, and lighting and service equipment—which are related to detailed design of a facility.

Table 3. Quantitative requirements of the standards.

\begin{tabular}{cccc}
\hline & UNE 100713:2015 & ASHRAE Standard 170-2017 & EN 16244 \\
\hline Temperature $\left({ }^{\circ} \mathrm{C}\right)$ & $22-26$ & $20-24$ & $18-24$ \\
RH $(\%)$ & $45-55$ & $20-60$ & $25-60$ \\
Overpressure (Pa) & $5-20$ & $\geq 2.5$ & $\geq 5$ \\
Filters & $\mathrm{F} 7+\mathrm{F} 9+\mathrm{H} 13$ & MERV 7 + MERV 14 & M5 + F7 + F9 + H13 \\
OA & $1200 \mathrm{~m}^{3} / \mathrm{h}$ & 4 over ACH & $275 \mathrm{~L} /$ pers. \\
ACH & $\geq 20$ & $\geq 20$ & Non-specified \\
Recovery time (min) & Based on UNE 171340 & Non-specified & Based on UNE 14644-3 \\
Supply air velocity (m/s) & $0.2-0.4$ & $0.13-0.18$ & $0.24-0.45$ \\
Sound pressure level (dBA) & $\leq 40$ & $40-50$ & $\leq 48$ \\
\hline
\end{tabular}

\section{Results}

The UNE 100713 standard establishes two types of premises according to the level of hygienic exigency required by the activity to be performed in the room. In this sense, we have operating room type A (with very high requirements) and operating room type B (standard requirements). 
Three categories of technical complexity for surgeries are no longer defined as in previous versions of ASHRAE Standard, but a single operating room definition is contemplated. However, its reference book still includes three kinds of surgeries (A, B, or C), with A being demanding of lower sepsis benefits and C being higher [18]. Finally, EN 16244 is based on ISO 14644 of International Organization for Standardization (ISO) classification which establishes environmental requirements in nine categories. In this way, a lower ordinal rating is assigned to rooms that demand higher performance, ISO 1; and lower performance demander, ISO 9. Operating room classification and air diffuser type recommended in accordance with standards are summarized in Table 4. Henceforth, a high-performance operating theatre where organ transplant surgeries, cardiac, aortic, orthopedic, burns, etc., are developed will be operating room Type A, Class $\mathrm{C}$, and ISO 5, according to this classification.

Table 4. Classification of operating theatres proposed by standards.

\begin{tabular}{lcl}
\hline & Classification & \multicolumn{1}{c}{ Air Diffuser } \\
\hline \multirow{2}{*}{ UNE 100713:2005 } & Type A & Unidirectional flow system \\
& Type B & Multi-directional or unidirectional flow system \\
\hline \multirow{3}{*}{ ASHRAE Standard 170-2017 } & Class A & Unidirectional flow diffuser \\
& Class B & Unidirectional flow diffuser \\
& Class C & Unidirectional flow diffuser array \\
\hline \multirow{2}{*}{ Pre-standard EN 16244 } & ISO 5 & Unidirectional flow diffuser array \\
& ISO 7 & Multi-directional flow \\
\hline
\end{tabular}

\section{Case Study}

In this case study, HVAC systems of a unidirectional flow operating room under design criteria of each standard were designed. CFD technology was employed to get quantitative results. A square room of $6.00 \mathrm{~m}$ sides and $2.85 \mathrm{~m}$ high was modeled. Five medical staff mannequins (two on each side of the surgical table and one on the patient's head) and the patient lying on the operating table, with defined physical characteristics of an adult of $1.75 \mathrm{~m}$ and $75 \mathrm{~kg}$, were modeled within the room. A $6.25 \mathrm{~m}^{2}$ square central air supply diffuser and $1036 \mathrm{~cm} \times 16 \mathrm{~cm}$ forced air exhaust grilles were installed. Mean values of the intervals proposed in the standards indicated in Table 4 were taken as design parameters. According to mass and energy balance, velocity, temperature, and $\mathrm{RH}$ of the supply air, the extraction flow ( $10 \%$ less than impulsion) and the temperature and $\mathrm{RH}$ of the people's surface $(307.15 \mathrm{~K}$ and $20 \%)$ to reach design parameters defined in Table 5 were defined as boundary conditions.

Table 5. Defined design parameters.

\begin{tabular}{cccc}
\hline & UNE 100713:2015 & ASHRAE Standard 170-2017 & EN 16244-2 \\
\hline Temperature (K) & 297.15 & 295.15 & 294.15 \\
RH (\%) & 50.00 & 40.00 & 40.25 \\
Pressurization $(\mathrm{Pa})$ & $5-20$ & $\geq 2.5$ & $\geq 5$ \\
Air velocity $(\mathrm{m} / \mathrm{s})$ & 0.30 & 0.15 & 0.345 \\
\hline
\end{tabular}

An example illustrates the number of ACHs performed by a unidirectional flow operating room with a large central diffuser. Thermal loads of the room caused by lighting $\left(20 \mathrm{~W} / \mathrm{m}^{2}\right)$, the occupation of six people $\left(500 \mathrm{w} / \mathrm{m}^{2}\right.$ sensible and $300 \mathrm{w} / \mathrm{m}^{2}$ latent), and typical equipment $(3.5 \mathrm{~kW})$ were considered [18]. $0.2 \mathrm{~m} / \mathrm{s}$ air velocity was taken as an intermediate value, among all proposed ranges supplied, across a drive area of $8 \mathrm{~m}^{2}$; so $5760 \mathrm{~m}^{3} / \mathrm{h}$ of air flow was entering the room. Considering the supply air flow rate and the volume of the room, a theoretical value of around $50 \mathrm{ACH}$ would be achieved. High-performance operating theatres with unidirectional flow systems are guaranteed to achieve the $\mathrm{ACH}$ proposed by the regulations. 
Figure 2 shows three views of the CFD study room model. Concretely, two views (perpendicular and longitudinal) are shown with respect to the operating table and a three-dimensional view of the room.

A comparison between the value of variables calculated as a result of the numerical model and predefined value for that same variable is shown in Figure 3 (air velocity is a boundary condition, not a result). The calculated value is a volume-average result. These boundary conditions are defined to reach predefined value. It is verified that the error between the average volume value and those defined as design parameters is negligible. This enables validation of the generated numerical model since there is a similarity between the expected value (calculated from design value according to heat and mass transfer laws) and calculated by numerical methods.

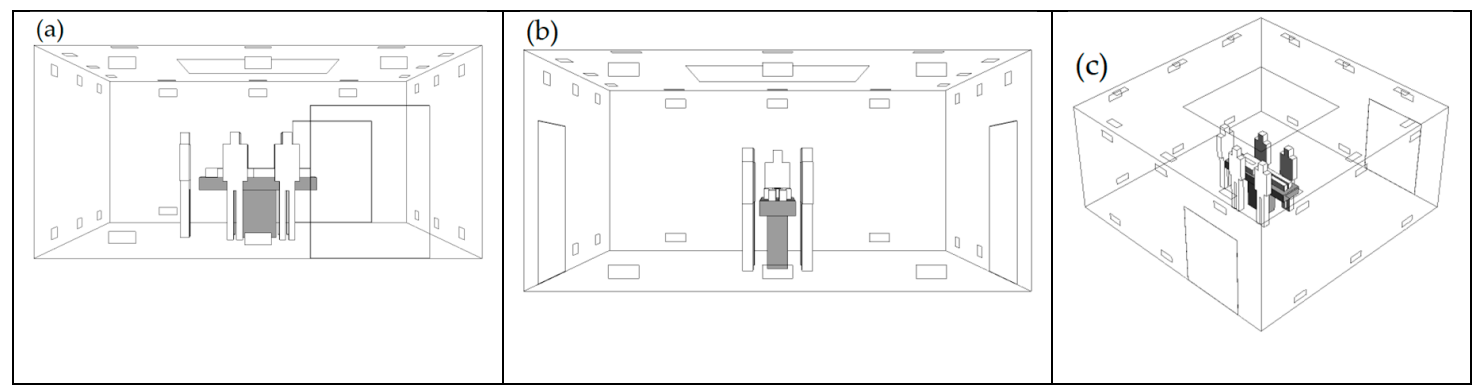

Figure 2. Geometry and arrangement of model elements. (a) lateral view, (b) frontal view, and (c) 3D view of the operating theatre.
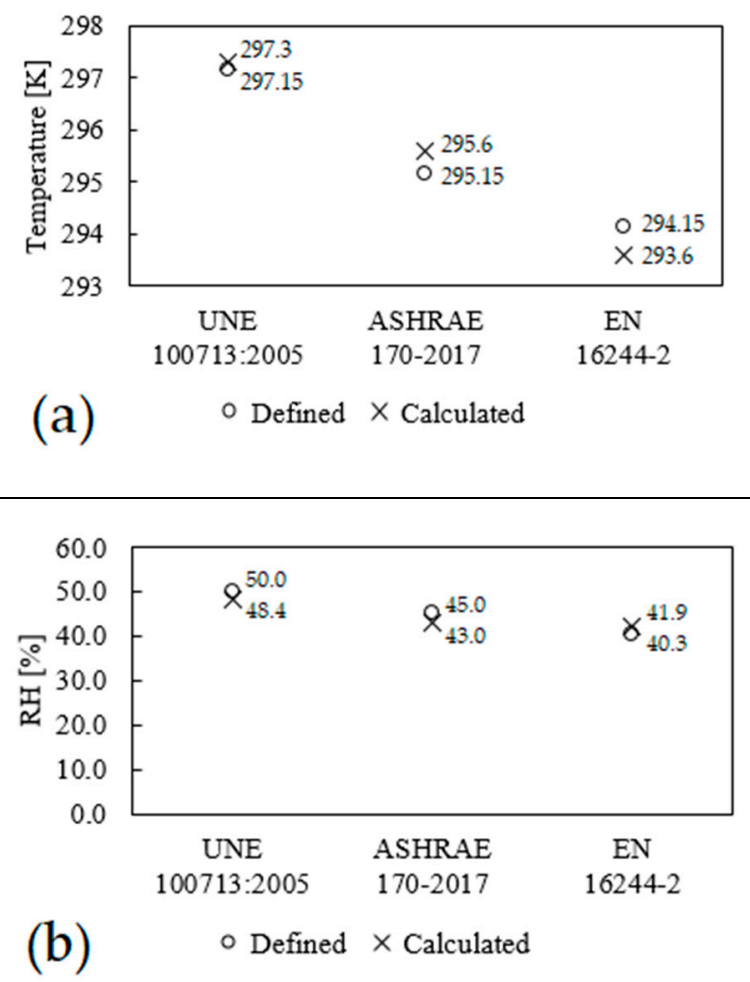

Figure 3. Cont. 


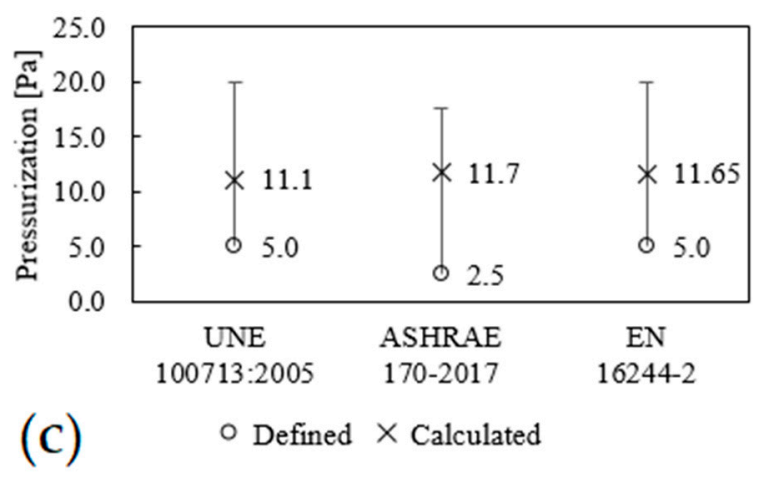

Figure 3. Quantitative results from computational fluid dynamics (CFD) study. (a) UNE 100713:2005,

(b) ASHRAE Standard 170-2017, and (c) pre-standard EN 16244-2.

Graphical results were extracted for a vertical plane passing through the longitudinal axis of the operating table. Figure 4 shows the contours of air temperature in the room. The highest temperatures were reached for UNE 100713 and the lowest for EN 16244-2, obtaining an intermediate value according to ASHRAE design. Temperature gradient around anesthetist and patient is represented by a succession of multiple contours. Both suffered a temperature gradient in a direction perpendicular to their body surface of $1.18 \mathrm{~K} / \mathrm{cm}$ in (a), $1.37 \mathrm{~K} / \mathrm{cm}$ in (b), and $1.55 \mathrm{~K} / \mathrm{cm}$ in (c) in their anterior part. Thus, the higher the average ambient temperature, the greater the temperature gradient of the body. The only non-covered area of the anesthetist's body was the face, which experienced this temperature difference. This was aggravated for the patient who is undressed.

Figure 5 shows the contours of air RH. The highest environmental RH value is given in UNE 100713 design, ASHRAE Standard has an intermediate value, and EN 16244-2 has the lowest environmental RH value. The patient and anesthetist were exposed to a gradient of RH in their anterior part of $3.75 \% / \mathrm{cm}$ in (a), $3.06 \% / \mathrm{cm}$ in (b), and $2.75 \% / \mathrm{cm}$ in (c), perpendicular to their body surface. Being exposed to a higher thermal gradient will affect their thermal comfort and health status.

Pressure distributions in the rooms are shown in Figure 6. A well-defined pressure stratification for design according to ASHRAE Standard 170, a minimum deformation for UNE 100713 design, and an appreciable deformation for EN 16244-2 design stratification was $0.124 \mathrm{~Pa} / \mathrm{m}$ in room (a), $0.112 \mathrm{~Pa} / \mathrm{m}$ in $(\mathrm{b})$, and $0.082 \mathrm{~Pa} / \mathrm{m}$ in (c) in a vertical perpendicular direction to the patient's body surface. The lowest pressure value occurred in the zone close to the ground in the three cases. These results are complemented by velocity results: the higher the air supply velocity, the greater the overpressure in the room and the greater the deformation of the pressure stratification.

Air velocity contours are shown in Figure 7. The highest drive speed was for the EN 16244-2 design and the lowest for the ASHRAE Standard design. The chosen impulsion speed is suitable for generating an ideal piston effect on the surgical field. Nevertheless, specific studies on cleanliness and particle removal would be needed to check if the air reached the protected area with sufficient velocity. The stele generated behind the anesthetist is worth noting, as it was formed behind the other four mannequins. The wake generated haven volumes in the air path loaded with bioparticles after dragging them. In corners and in lower parts of the table, these haven zones were also generated. This will involve the deposition of airborne bioparticles due to loss of air transport capacity. 
(a)

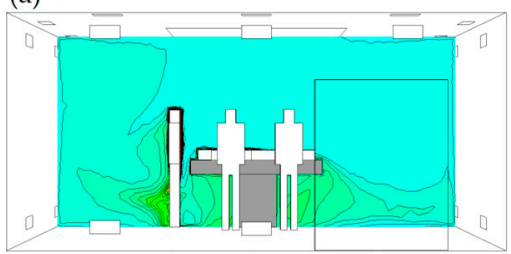

(b)

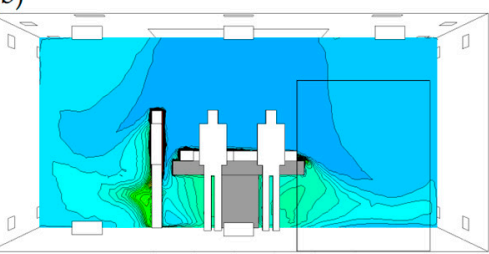

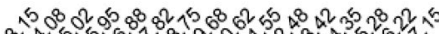

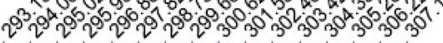

(c)

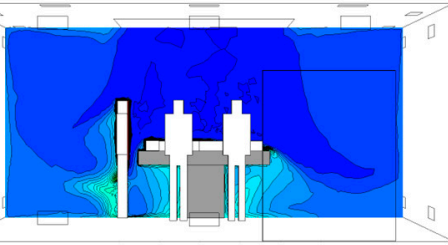

Temperature

Figure 4. Air temperature contours. Each room was designed based on: (a) UNE 100713:2005, (b) ASHRAE Standard 170-2017, (c) pre-standard EN 16244-2.

(a)

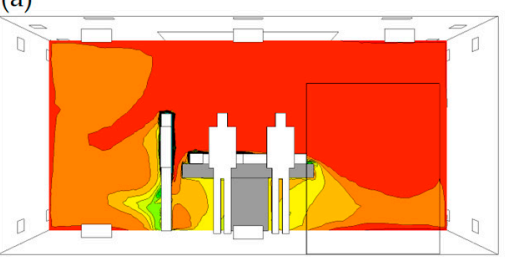

(b)

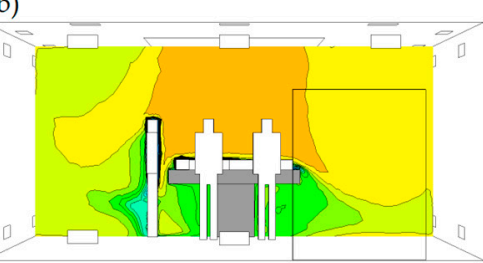

(c)

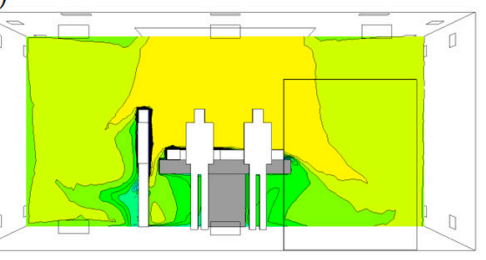

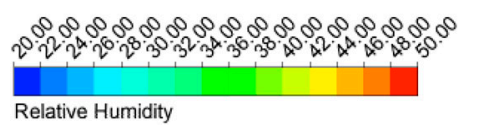

Figure 5. Air relative-humidity (RH) contours. Each room was designed based on: (a) UNE 100713:2005, (b) ASHRAE Standard 170-2017, (c) pre-standard EN 16244-2.

(a)
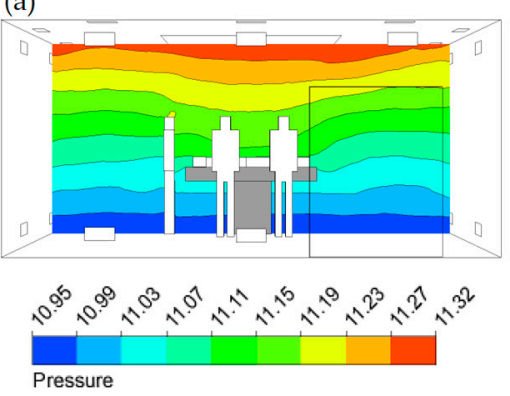

(b)
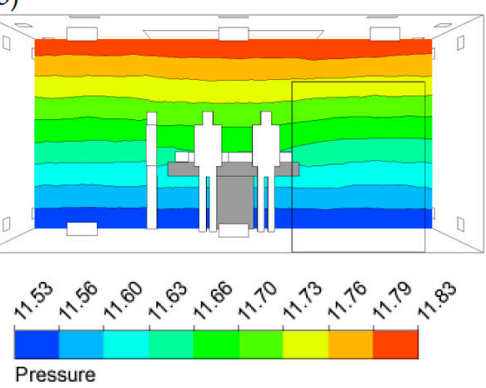
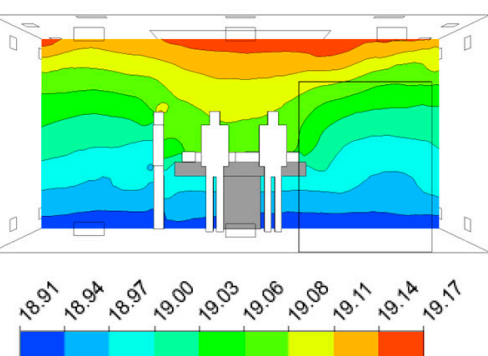

Pressure

Figure 6. Pressure distribution contours. Each room was designed based on: (a) UNE 100713:2005, (b) ASHRAE Standard 170-2017, (c) pre-standard EN 16244-2.

(a)

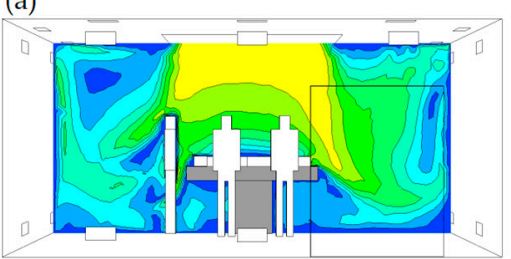

(b)

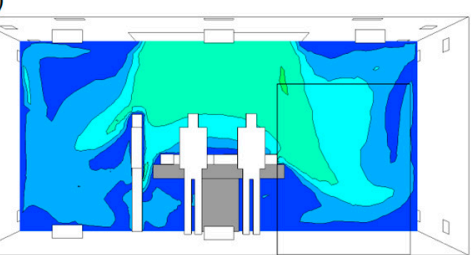

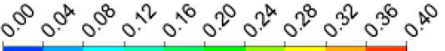

$$
\begin{aligned}
& \text { Velocity }
\end{aligned}
$$

(c)

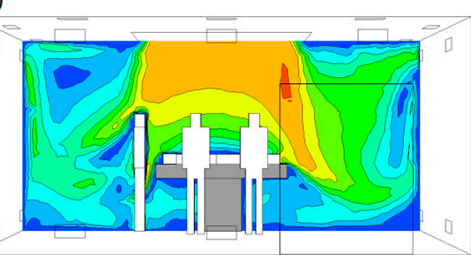

Figure 7. Air velocity contours. Each room was designed based on: (a) UNE 100713:2005, (b) ASHRAE Standard 170-2017, (c) pre-standard EN 16244-2. 


\section{Discussion}

The recommended temperature range is $18-24{ }^{\circ} \mathrm{C}$ as a whole. Certain surgeries require lower temperature (deep and organ surgery) or higher temperature (pediatric surgery) [33]. Research has revealed the influence of clothing and activity level on thermal comfort so that nurses and anesthetists will be comfortable at $23-24{ }^{\circ} \mathrm{C}$, surgeons at $18-19{ }^{\circ} \mathrm{C}$, and patients at $24.5-25.5^{\circ} \mathrm{C}$ [5]. A temperature higher than $23^{\circ} \mathrm{C}$ is hardly bearable for surgeons [44]; nevertheless, the risk of hypothermia exists for patient below $21^{\circ} \mathrm{C}$ [45]. Electromedical equipment and surgical lights have a direct influence on indoor temperature distribution causing asymmetry and/or stratification of air temperatures [5].

Values proposed for $\mathrm{RH}$ by the standards are different, but the maximum value of $60 \%$ is shared. The widest range is covered by ASHRAE Standard (20\%-60\%), while the narrowest is for UNE 100713 (45\%-55\%). Not limiting RH value favors the proliferation of bacteria for extreme values in both senses [18], favors blood coagulation, while a dry environment makes staff uncomfortable and sweating is favored when RH is high. The humidification process in air conditioning is critical and must be backed up by an adequate maintenance plan [46]. The standards allow regulation of values within defined ranges for thermal comfort (temperature and RH), so they can be modified if necessary, for medical requirements.

It has been proven that overpressure of the room is reached by mechanical means extracting an air flow lower than the driven one [47]. This parameter favors protection of the room against cross-contamination since it induces circulation of air from the clean zone to less clean corridors and adjoining rooms inside the surgical block. Overpressure in the room prevents potentially contagious bioparticles entering, complementing the filters' work. Recommended minimum pressurization value is positive for maintaining operating rooms as protected areas. At this point, it is worth wondering whether a value of 2.5 Pa established by ASHRAE Standard and 5 Pa in EN 16244-2 is adequate to favor and maintain this air circulation among rooms or, on the contrary, this value is insufficient. A great deal of rigor is required from operating theatre medical staff to achieve and maintain pressurization in the room. Avoiding entrance and exit of personnel and materials during surgery is recommended [8] since the doors opening during surgery entails the complete loss of ventilation system effectiveness [48] and an increase in air residence time [49].

Ultra-clean air must be supplied to high-performance operating rooms to prevent entrance of microorganisms or other pathogens from the outside environment. EN 16244-2 adds a new filtration stage by means of a pre-filter (M5) installed on top of stages already recommended in UNE 100713 standard: F7 ( $\varepsilon=80 \%-90 \%), \mathrm{F} 9(\varepsilon>95 \%)$, and H13 ( $\varepsilon=99.95 \%)$. This will improve the filter stages' performance by lengthening their useful life. This recommendation strongly disagrees with the ASHRAE Standard, which proposes two lower-efficiency filter stages. The first filtering level will be through MERV 7 filter and the second one will be through MERV 14 filter. Both filter levels match a G4 filter $(\varepsilon<90 \%)$ and F8 $(\varepsilon=90 \%-95 \%)$ according to ISO 16890-1 [50]. They agree to place the high-efficiency filter in a drive terminal unit. None of the standards contemplates ultraviolet germicidal irradiation, being an effective germicidal method [33].

$\mathrm{ACH}$ is performed to decrease the microbiological load generated within the operating room. $\mathrm{ACH}$ allows for the dilution of anesthetic gases and surgical smoke concentration inside the room, therefore, a much higher number of $\mathrm{ACH}$ will be performed compared to other types of rooms. Infection risk increases with bioparticles concentration due to its increased viability as a pathogen [51]. Anesthetic gas concentration increases can be caused by a leak in equipment or due to bad practical execution, and the surgical smoke increase is derived from electrosurgery, laser, or ultrasound use [52]. The recommended minimum value of ACH is very similar in UNE 100713 and ASHRAE Standard 170, however, this parameter is not specified in EN 16244-2. On the one hand, increasing the amount of fresh air impelled improves dilution effectiveness [53] but, on the other hand, it does not guarantee an SSI rate decrease and, nevertheless, operating costs are always raised [54]. Infection hazard is reduced by controlling air movement pattern [52,55] which leads to an equipment expenditure and operating costs reduction. OA discharge into a room through the HVAC system also contributes 
to lowering the concentration of medical gases and surgical smoke generated during surgery. UNE 100713 sets a minimum OA flow value in volumetric flow units. Nonetheless, EN 16244-2 prescribes it according to the number of people in the room. The number of people attending surgery is variable, which will cause the value of this parameter to change. This requirement is therefore not easy to implement since an automatic control system that regulates $\mathrm{OA}$ flow according to the occupation of the room is necessary. ASHRAE Standard 170 states that four over $20 \mathrm{ACH}$ shall be performed by OA. Air recirculated to the room should pass through filtration stages to ensure its charge of particles.

The room recovery time concept is not contemplated by ASHRAE Standard although it is included in Spanish and European standards. However, the reference standard used to define a room recovery test is different: UNE 100713 applies another Spanish standard (UNE 171340: 2012 [56]) and pre-standard EN 16244-2 reference ISO 14644-3. It should be noted that UNE 171340 is specifically aimed at hospital wards, while ISO 14644-3 is for controlled environment rooms in general. The Center for Disease Control proposes an equation to determine room recovery time based on initial concentration, room volume, airflow, and ACH [8].

Surgical field cleaning in high-performance operating theatres is achieved by the piston effect. The piston effect is generated by unidirectional flow diffusers. It is possible to obtain an adequate air movement pattern by driving ultra clean air at an adequate velocity, across a given surface and being extracted from the room by strategic locations. Air impulsion velocity in a terminal unit located above the surgical field must be sufficient to maintain unidirectionality when going through a protected zone and to ensure particle dragging by piston effect [57]. In order to maintain unidirectionality of flow, air must have a certain velocity and turbulence lower than 5\% [18]. Too high velocity will cause airflow swirls re-entering surgical field and/or decreasing bioparticle removal efficacy. Obstacles to maintaining unidirectional airflow are, first, physical elements such as luminaires and personnel present; and, second, the thermal contour of people and equipment. ASHRAE Standard recommends a maximum air supply velocity value of $0.18 \mathrm{~m} / \mathrm{s}$, a minimum in UNE $100713 \mathrm{of} 0.20 \mathrm{~m} / \mathrm{s}$, and in EN 16244- $20.24 \mathrm{~m} / \mathrm{s}$. The values of ASHRAE are based on the work of Memarzadeh and Manning [4] and Rui et al. [24] and are much lower than those proposed in the other two standards under study. However, there are research projects [22] that support the stated in UNE 100713 and EN 16244-2. Forced air exhaust location determines air movement pattern generated. A strategic location of grilles will cause air to trace a certain path towards the outlet, consequently improving dilution rate (cleaning, particle removal, etc.).

It has been proven that medical personnel subjected to a sound pressure level influence their fatigue and, therefore, their performance in medical-surgical practice [58]. The ASHRAE criterion is the most tolerant while UNE 100713 is the most restrictive. Pre-standard EN 16244-2 specifies a limit of $48 \mathrm{dBA}$, closer to the AHSRAE limit than to the UNE standard. No other studies have been found on the influence of sound pressure level on acoustic comfort in operating theatres.

Aforementioned standard UNE 171340:2012 [56] is used to validate and qualify controlled environment rooms in hospitals. It evaluates a series of environmental and facility parameters. Environmental parameters are temperature and $\mathrm{RH}$, microbiology, bioparticles classification, and sound pressure level; facility parameters are differential pressure, absolute filter location, airflows and $\mathrm{ACH}$, airflow direction, and room recovery test. In addition, energetic and environmental saves can be achieved [59].

Default value ranges for parameters are different in standards applicable to a single country. It reveals the disparity of baseline criteria for defining guidelines and standards and causes designers to face technical indecision to ensure patient and caregiver safety. Adequate value of each parameter is chosen in order to minimize infection risk. The international nature of the standards analyzed allows the results of this work to be applicable to other countries since surgeries demand similar hygienic levels all over the world.

Future works should be aimed at adapting the value of each design parameter to the conditions of each surgery. Multivariable tables and/or abacus can be obtained to define suitable environmental 
conditions according to the type of surgery. In this way, it will be possible to integrate people's thermal comfort, maintaining safety and sterility levels during surgery. Analyses using CFD technology will play a crucial role.

\section{Conclusions}

Design parameters of HVAC installations in high-performance hospital operating theatres were evaluated according to UNE 100713, ASHRAE Standard 170, and pre-standard EN 16244-2. All of them establish a range of values for thermohygrometric conditions.

It was found that ASHRAE Standard was the most tolerant in values proposed for room overpressure. Pre-standard maintains the minimum value proposed by UNE standard but does not define a maximum, so in both, the value of this parameter is at designer criteria. ASHRAE Standard recommends a smaller number of filtering stages and less efficiency. The pre-standard adds an additional level of pre-filtering over UNE standard.

It was noticed that the unit used to define OA flow recommended by EN 16244 is of difficult practical implementation, however, UNE and ASHRAE standards establish a more feasible way to define it. Nonetheless, Standard 170 does not contemplate room recovery time concept for study standards, as UNE 100713 and EN 16244-2 do. A minimum drive speed of $0.07 \mathrm{~m} / \mathrm{s}$ and $0.11 \mathrm{~m} / \mathrm{s}$ less than UNE and EN 16244-2, respectively, is proposed by ASHRAE. In addition, its maximum value is lower than the minimum proposed in the other two standards. There is a similar discrepancy in the scientific literature regarding this parameter. The most restrictive sound pressure level is for UNE 100713.

Huge temperature and RH gradients $(1.18 \mathrm{~K} / \mathrm{cm}$ and $3.75 \% / \mathrm{cm}$ in UNE $100713,1.37 \mathrm{~K} / \mathrm{cm}$ and $3.06 \% / \mathrm{cm}$ in ASHRAE 170 , and $1.55 \mathrm{~K} / \mathrm{cm}$ and $2.75 \% / \mathrm{cm}$ in EN $16244-2$, respectively) highlight the importance of adapting the values of these parameters to the patient's health status to ensure their safety and taking into account the thermal comfort of medical staff to improve their medical-surgical performance. CFD studies can quantify the pressure gradient due to stratification generated in the room $(0.124 \mathrm{~Pa} / \mathrm{m}$ in UNE $100713,0.112 \mathrm{~Pa} / \mathrm{m}$ in ASHRAE 170 , and $0.082 \mathrm{~Pa} / \mathrm{m}$ in EN 16244). They also make it possible to detect areas of haven that constitute microbiological load accumulation areas. In this way, cleaning protocols can be defined to avoid consequences in a preventive way.

The soundness of the results obtained is related to their appropriateness to characteristics of surgery performed. It was detected that different results are obtained in order to design a room according to the regulation employed. It was proven that CFD technology is an adequate tool to obtain performance evaluations of installations prior to construction. It even allows the inverse process to be established, i.e., desired pressurization, temperature, and $\mathrm{RH}$ values are defined, and the value of boundary conditions is calculated as a result.

Author Contributions: Conceptualization, J.G.S.-C.; data curation, G.S.-B.; formal analysis, J.G.S.-C.; investigation, G.S.-B. and J.G.S.-C.; methodology, G.S.-B.; software, G.S.-B.; supervision, J.G.S.-C.; validation, J.G.S.-C.; writing-original draft, G.S.-B.

Funding: This research received no external funding.

Acknowledgments: The authors wish to acknowledge to the Junta de Extremadura and the European Social Found (FEDER) for the support of this research work. This study has been carried out through the Research Project GR-18029 linked to the VI Regional Plan for Research, Technological Development and Innovation from the General Government of Extremadura 2017-2020.

Conflicts of Interest: The authors declare no conflict of interest.

\section{References}

1. Memarzadeh, F.; Manning, A. Reducing risk of surgery. ASHRAE J. 2003, 45, 28-33.

2. Whyte, W.; Hodgson, R.; Tinkler, J. The importance of airborne bacterial contamination of wounds. J. Hosp. Infect. 1982, 3, 123-135. [CrossRef] 
3. Lidwell, O.; Lowbury, E.; White, W.; Blowers, R.; Stanley, S.; Lowe, D. Airborne contamination of wounds in joint replacement operations: The relationship to sepsis rates. J. Hosp. Infect. 1983, 4, 111-131. [CrossRef]

4. Memarzadeh, F.; Manning, A. Comparison of operating room ventilation systems in the protection of the surgical site. ASHRAE Trans. 2002, 108, 3-15.

5. Mora, R.; English, M.; Athienitis, A. Assessment of Thermal Comfort during Surgical Operations. ASHRAE Trans. 2001, 107, 65-74.

6. Kuehn, T. Airborne infections control in health care facilities. J. Sol. Energy Eng. 2003, 125, 366-371. [CrossRef]

7. Drake, B. Infection control in hospitals. ASHRAE J. 2006, 48, 12-17. [CrossRef]

8. Berríos-Torres, S.I.; Umscheid, C.A.; Bratzler, D.W.; Leas, B.; Stone, E.C.; Kelz, R.R.; Reinke, C.E.; Morgan, S.; Solomkin, J.S.; Mazuski, J.E.; et al. Centers for Disease Control and Prevention Guideline for the Prevention of Surgical Site Infection, 2017. JAMA Surg. 2017, 152, 784-791. [CrossRef]

9. González, A.G.; García-Sanz-Calcedo, J.; Salgado, D.R. A quantitative analysis of final energy consumption in hospitals in Spain. Sustain. Cities Soc. 2018, 36, 169-175. [CrossRef]

10. Biscione, F. Rates of surgical site infection as a performance measure: Are we ready? World J. Gastrointest. Surg. 2009, 1, 11-15. [CrossRef]

11. Alexakis, P.; Feldon, P.; Wellisch, M.; Richter, R.; Finegold, S. Airborne bacterial contamination of operative wounds. West. J. Med. 1976, 124, 361-369.

12. Andersson, A.; Bergh, I.; Karlsson, J.; Ericsson, B.; Nilsson, K. Traffic flow in the operating room: An explorative and descriptive study on air quality during orthopaedic trauma implant surgery. Am. J. Infect. Control 2012, 40, 750-755. [CrossRef]

13. Pittet, D.; Ducel, G. Infectious Risk Factors Related to Operating Rooms. Infect. Control Hosp. Epidemiol. 1994, 15, 456-462. [CrossRef]

14. Spagnolo, A.; Ottria, G.; Amicizia, D.; Perdelli, F.; Cristina, M. Operating theatre quality and prevention of surgical site infections. J. Prev. Med. Hyg. 2013, 54, 131-137.

15. García Sanz-Calcedo, J.; Monzón, P. Analysis of the economic impact of environmental biosafety works projects in healthcare centres in Extremadura (Spain). DYNA Colomb. 2014, 81, 100-105. [CrossRef]

16. Li, Y.; Leung, G.M.; Tang, J.W.; Yang, X.; Chao, C.Y.; Lin, J.Z.; Lu, J.W.; Nielsen, P.V.; Niu, J.; Qian, H.; et al. Role of ventilation in airborne transmission of infectious agents in the built environment-A multidisciplinary systematic review. Indoor Air 2007, 17, 2-18. [CrossRef]

17. Chiang, C.Y.; Yang, R.; Yang, K.H.; Lee, S.K. Performance Analysis of an Integrated Heat Pump with Air-Conditioning System for the Existing Hospital Building Application. Sustainability 2017, 9, 530. [CrossRef]

18. American Society of Heating, Refrigerating and Air-Conditioning Engineers (ASHRAE). HVAC Design Manual for Hospitals and Clinisc; American Society of Heating, Refrigerating and Air-Conditioning Engineers (ASHRAE): Atlanta, GA, USA, 2013.

19. Spengler, J. Indoor Air Quality Handbook; McGraw-Hill Education: New York, NY, USA, 2001.

20. Fonseca, A.; Abreu, I.; Guerreiro, M.J.; Abreu, C.; Silva, R.; Barros, N. Indoor Air Quality and Sustainability Management-Case Study in Three Portuguese Healthcare Units. Sustainability 2019, 11, 101. [CrossRef]

21. Fanger, P. Thermal Comfort: Analysis and Applications in Environmental Engineering; Danish Technical Press: Copenhagen, Denmark, 1970.

22. Chow, T.; Yang, X. Performance of ventilation system in a non-standard operating room. Build. Environ. 2003, 38, 1401-1411. [CrossRef]

23. International Organization for Standarization. ISO 14644 Cleanrooms and Associated Controlled Environments. Available online: https: / www.iso.org/standard/69432.html (accessed on 27 February 2019).

24. Rui, Z.; Guangbei, T.; Jihong, L. Study on biological contaminant control strategies under different ventilation models in hospital operating room. Build. Environ. 2008, 43, 793-803. [CrossRef]

25. NF S 90-351: Clean Rooms and Related Controlled Environments in Medical Establishments. Available online: http:/ / ata-medical.com/brochures/room_dopair_eng.pdf (accessed on 27 February 2019).

26. DIN 1946: Ventilation and Air-Conditioning_Part 4: Ventilation in Hospitals; Deutsches Institut für Normung: Berlin, Germany, 2018.

27. SWKI 99-3: Heating, Ventilation and Air-Conditioning in Hospitals; Swiss Association of Heat and Climate Engineers: Bern, Switzerland, 2003.

28. JIS-B 9920 Classification of Air Cleanliness for Cleanrooms; Japanese Industrial Standard: Tokyo, Japan, 2002. 
29. UNI 11425:2011 Pollution-Controlled Air-Conditioning and Ventilation System (CCPV) for the Operating Block-Design, Installation, Commissioning, Qualification, Operation and Maintenance; Ente Italiano di Normazione: Rome, Italy, 2011.

30. HTM 01-03 Heating and Ventilation Systems, Specialised Ventilation for Healthcare Premises, Part A: Design and Validation; Department of Health and Social Care: London, UK, 2007.

31. Melhado, M.; Hensen, J.; Loomas, M.; Forejt, L. Review of operating room ventilation standards. In Proceedings of the 17th International Air-Conditioning and Ventilation Conference, Prague, Czech Republic, 17-19 May 2006.

32. Nastase, I.; Croitorua, C.; Vartiresa, A.; Tataranub, L. Indoor Environmental Quality in Operating Rooms: A European Standard Review with regard to Romanian Guidelines. Energy Procedia 2016, 85, 375-382. [CrossRef]

33. Balaras, C.; Dascalaki, E.; Gaglia, A. HVAC and indoor thermal conditions in hospital operating rooms. Energy Build. 2007, 39, 454-470. [CrossRef]

34. Khodakarami, J.; Nasrollahi, N. Thermal comfort in hospitals - A literature review. Renew. Sustain. Energy Rev. 2012, 16, 4071-4077. [CrossRef]

35. Iudicello, S.; Fadda, A. A Road Map to a Comprehensive Regulation on Ventilation Technology for Operating Rooms. Infect. Control Hosp. Epidemiol. 2013, 34, 858-860. [CrossRef] [PubMed]

36. UNE 100713:2005 Air Conditioning in Hospitals; Asociación Española de Normalización (AENOR): Madrid, Spain, 2005.

37. ANSI/ASHRAE/ASHE Standard 170-2017 Ventilation of Health Care Facilities; American Society of Heating, Refrigerating and Air-Conditioning Engineers: New York, NY, USA, 2017.

38. EN 16244 Ventilation in Hospitals; European Committee for Standardization: Brussels, Belgium, 2018.

39. Zhai, Z.; Zhang, Z.; Zhang, W.; Chen, Q. Evaluation of Various Turbulence Models in Predicting Airflow and Turbulence in Enclosed Environments by CFD. Part-1: Summary of Prevalent Turbulence Models. HVACER Res. 2007, 13, 853-870. [CrossRef]

40. ANSYS Fluent 17.0-Theory Guide; ANSYS Inc.: Cannonsburg, PA, USA, 2016.

41. Hsieh, K.; Lien, F. Numerical modeling of buoyancy-driven turbulent flows in enclosures. Int. J. Heat Fluid Flow 2004, 25, 659-670. [CrossRef]

42. Chen, Q.; Srebric, J. Application of CFD tools for indoor and outdoor environment design. Int. J. Archit. Sci. 2000, 1, 14-29.

43. ISO 14698:2003 Cleanrooms and Associated Controlled Environments; International Organization for Standardization: Bern, Switzerland, 2003.

44. Leslie, K.; Sessler, D. Perioperative Hypothermia in the high-risk surgical patient. Best Pract. Res. Clin. Anaesthersiol. 2007, 17, 485-498. [CrossRef]

45. Johnston, I.; Hunte, A. The Design and Utilization of Operating Theatres; Edward Arnold: London, UK, 1984.

46. García Sanz-Calcedo, J.; Gómez-Chaparro, M. Quantitative Analysis of the Impact of Maintenance Management on the Energy Consumption of a Hospital in Extremadura (Spain). Sustain. Cities Soc. 2017, 30, 217-222. [CrossRef]

47. Sánchez-Barroso, G.; García Sanz-Calcedo, J.; González, A.G. Influence of Air Pressure on Unidirectional Flow Operating Theatres: A Study Based on Computational Fluid Dynamics. In Proceedings of the 2nd International Symposium on Computer Science and Intelligent Control, Stockholm, Sweden, 21-23 September 2018. [CrossRef]

48. Lydon, P.; Ingham, D.; Mourshed, M. Ultra clean ventilation system performance relating to airborne infections in operating theatres using CFD modelling. Build. Simul. 2014, 7, 277-287. [CrossRef]

49. Attia, A.; Helw, M.; Teamah, H.A. Three-dimensional thermal comfort analysis for hospital operating room with the effect of door gradually opened. Part II: Effect on mean age of the air and predicted mean vote distribution. CFD Lett. 2013, 5, 20-31.

50. ISO 16890-1: 2016 Air Filters for General Ventilation-Part 1: Technical Specifications, Requirements and Classification System Based upon Particulate Matter Efficiency; International Organization for Standardization: Bern, Switzerland, 2016.

51. Humphreys, H.; Taylor, E. Operating theatre ventilation standards and the risk of postoperative infection. J. Hosp. Infect. 2002, 50, 85-90. [CrossRef] [PubMed] 
52. Gómez-Chaparro, M.; García Sanz-Calcedo, J.; Armenta-Márquez, L. Analytical Determination of Medical Consumption and their Impact on Hospital Sustainability. Sustainability 2018, 10, 2948. [CrossRef]

53. Faulkner, W.B.; Memarzadeh, F.; Riskowski, G.; Kalbasi, A.; Ching-Zu Chang, A. Effects of air exchange rate particle size and injection place on particle concentrations within a reduced-scale room. Build. Environ. 2015, 92, 246-255. [CrossRef]

54. Gormley, T.; Markel, T.A.; Jones, H.; Greeley, D.; Ostojic, J.; Clarke, J.H.; Abkowitz, M.; Wagner, J. Cost-benefit analysis of different air changes rates in an operating room environment. Am. J. Infect. Control 2017, 45, 1318-1323. [CrossRef] [PubMed]

55. Memarzadeh, F.; Xu, W. Role of air changes rate per hour (ACH) in possible transmission of airborne infections. Build. Simul. 2012, 5, 15-28. [CrossRef]

56. UNE 171340:2012 Validation and Evaluation of Controlled Environment Rooms in Hospitals; Asociación Española de Normalización: Madrid, Spain, 2012.

57. Tinker, J.; Roberts, D. Indoor air quality and infection problems in operating theatres. In Proceedings of the 2nd European Conference on Energy Performance and Indoor Climate in Buildings, Lyon, France, 19-21 November 1998.

58. Sykes, D.; Tocci, G.; Cavanaugh, W. Sound E Vibration: Design Guidelines for Health Care Facilities; Springer Science \& Business Media: New York, NY, USA, 2013.

59. García-Sanz-Calcedo, J.; Al-Kassir, A.; Yusaf, T. Economic and environmental impact of energy saving in healthcare buildings. Appl. Sci. 2018, 8, 440. [CrossRef]

(C) 2019 by the authors. Licensee MDPI, Basel, Switzerland. This article is an open access article distributed under the terms and conditions of the Creative Commons Attribution (CC BY) license (http://creativecommons.org/licenses/by/4.0/). 